\title{
Schizophrenia: what's new?
}

\author{
Robin McCreadie
}

When I was asked to write an introduction to a series of papers on schizophrenia, I went through the back issues of Advances in Psychiatric Treatment (APT) to remind myself what topics had already been covered. I was very surprised to find that of over 130 articles published between 1994 and 1998, only about 10 dealt specifically with schizophrenia or its treatment. Why is this? Is there nothing new to say about schizophrenia? Have there been no recent advances in management? Surely not. Is it rather that schizophrenia is currently unfashionable? Are topics such as false memory syndrome, gender dysphoria and cross-cultural issues of more interest to today's psychiatrist?

I hope we are not going the way of American psychiatry. When I attended the American Psychiatric Association (APA) annual meeting in Toronto last year (1998) I visited the APA book display, which appeared to cover several acres. There were only one-and-a-half bookshelves devoted to texts on schizophrenia and half a bookshelf to bipolar disorders. Bookcase after bookcase was devoted to the topics I have mentioned above.

Schizophrenia and the management of patients suffering from this disorder must remain the bread and butter of the general psychiatrist. Although the incidence is low, the prevalence is high, as it is a chronic condition. In a general psychiatrist's 'patch' of say 30 000, there will at any time be 100150 people with schizophrenia. Most of these patients will be living outside hospital and many, if not the majority, will have significant mental state abnormalities. Drug side-effects are common, social adjustment may be poor and physical health impaired (Kelly et al, 1998).

Much needs to be done, therefore, to improve the lot of the patient with schizophrenia. A series of articles in future issues of APT will cover important areas.
The vast bulk of schizophrenia research has excluded children and younger adolescents with psychotic disorders. Is schizophrenia the same disorder when diagnosed in childhood and adolescence compared with adult life? What is the special significance, if any, of the atypical early onset of schizophrenia in childhood and adolescence? Perhaps some myths about adolescent schizophrenia need to be exploded.

It has long been known that the earlier treatment starts, the better the long-term prognosis (Loebel et $a l, 1992)$. Less clear are the benefits of trying to detect relapse at an early stage and how to manage such patients when identified. What treatments should be used? How does this affect the course of the illness, in both the short and the long term?

Much emphasis has been placed on the positive and negative symptoms of schizophrenia. However, depressive symptoms are common. Also, it is increasingly recognised that cognitive, especially memory, impairment is an integral part of the disease process (McKenna et al, 1990). How many times have we heard a patient say, "I'm sorry, doc, I forgot my appointment" and put it down to poor compliance, or 'concordance'. In fact, in many cases, they probably did forget. Cognitive impairment may be associated with poor psychosocial functioning in the community (Green, 1996). 'Cognitive remediation' may be helpful with some patients.

Drugs have always been a mainstay of treatment of schizophrenia. The introduction of atypical antipsychotics has raised many issues. They are certainly effective and cause less in the way of extrapyramidal side-effects (Kerwin, 1994), but they are expensive. If they are to be used as a first-line treatment (my own personal view), which one should be used in which situation?

As stated above, the standard drugs, and to a much lesser extent the atypicals, produce motor

Robin McCreadie is Director of Clinical Research and a consultant psychiatrist at Crichton Royal Hospital (Dumfries, DG1 4TG, Scotland). His main research interest is in the field of schizophrenia and he has published widely on the cohort of Nithsdale patients with schizophrenia. He is the founder of the Scottish Schizophrenia Research Group. 
side-effects, especially parkinsonism and tardive dyskinesia. In the most recent Nithsdale survey (Kelly et al, 1998), the prevalence of the former was $28 \%$ and the latter $41 \%$. How should such disorders be managed?

The physical health of patients with schizophrenia has long been ignored. However, patients with schizophrenia die early (Mortensen \& Juel, 1990). Suicide in younger patients with schizophrenia is well-recognised but the most common cause of natural death is cardiovascular disease, where diet and smoking are the two most important aetiological factors. The diet of patients with schizophrenia is poor (McCreadie et al, 1998), and most have started smoking before the first episode of illness (Kelly \& McCreadie, 1999). We urgently need management strategies to help these patients stop smoking.

Community care is here to stay. Strident calls that community care has failed ignore reality: most patients with schizophrenia live outside hospital, and most prefer to do so. They live quietly; they are law-abiding. None the less, for community care to be successful, patients must remain in touch with a psychiatric service and have rapid access, if necessary, to the help it can provide. Throughout the $\mathrm{UK}$, the community psychiatric nurse $(\mathrm{CPN})$ is a prominent member of the community mental health team. But what does a CPN do, apart from give longacting intramuscular injections? What skills do CPNs have that psychiatrists, social workers or psychologists do not? In a developing country such as India, where the family rallies round to look after a relative with schizophrenia, a 'community' nurse is an alien concept. What are the advantages, if any, of having a psychiatric nurse involved in the community management of patients with schizophrenia?

Unfortunately, there is a tiny minority of patients with schizophrenia in the community who do fall foul of the law. The offences in the main are trivial, but occasionally they are more serious. If the offence is intimately related to the illness (it often is not), then admission to a hospital with secure facilities rather than prison is the best disposal. But what happens to patients when they go there? What is the best way to manage them? Where are the boundaries between security and treatment? Who should decide?

Forensic issues spill over into the community. How can we ensure that patients will continue to receive treatment once they have been discharged from hospital? The mental health acts within the UK are currently under review. Radical changes are necessary if patients are to be managed successfully outside hospital.

In summary, the use of new drugs and psychological techniques, close attention to physical health, and the implementation of different ways of community management deserve the attention of a general adult psychiatrist. Much can and should be done to improve further the health of patients with schizophrenia. These are some of the issues that will be covered in the forthcoming series of articles on schizophrenia.

\section{References}

Green, M. F. (1996) What are the functional consequences of neurocognitive deficits in schizophrenia? American Journal of Psychiatry, 153, 321-330.

Kelly, C., McCreadie, R. G., MacEwan, T., et al (1998) The Nithsdale schizophrenia surveys. 17. Fifteen year review. British Journal of Psychiatry, 172, 513-517.

_ \& _ (1999) Smoking habits, current symptoms and premorbid characteristics of schizophrenic patients in Nithsdale, Scotland. American Journal of Psychiatry, 156, 1751-1757.

Kerwin, R. W. (1994) The new atypical antipsychotics. A lack of extrapyramidal side-effects and new routes in schizophrenia research. British Journal of Psychiatry, 164, 141-148.

Loebel, A. D., Lieberman, J. A., Alvir, J. M., et al (1992) Duration of psychosis and outcome in first-episode schizophrenia. American Journal of Psychiatry, 149, 1183-1188.

McCreadie, R. G., MacDonald, E., Blacklock, C., et al (1998) Dietary intake of schizophrenic patients in Nithsdale, Scotland: case control study. British Medical Journal, 317, 784785 .

McKenna, P. J., Tamlyn, D., Lund, C. E., et al (1990) Amnesic syndrome in schizophrenia. Psychological Medicine, 20, 967972.

Mortensen, P. B. \& JueL, K. (1990) Mortality and cause of death in schizophrenic patients in Denmark. Acta Psychiatrica Scandinavica, 81, 372-377. 